\title{
The ultrasonographic determination of the position of the mental foramen and its relation to hard tissue landmarks
}

\author{
Abdullah Ebrahim Laher, Zeyn Mahomed \\ Division of Emergency Medicine \\ Charlotte Maxeke Johannesburg \\ Academic Hospital, University of \\ the Witwatersrand South Africa

\footnotetext{
${ }^{*}$ Corresponding author: abdullahlaher@msn.com Tel.: + 27848402508 Fax.: + 27118430646
} \\ Received: 14 January 2016 \\ Accepted: 6 April 2016 \\ Key words: Ultrasound - Mental foramen \\ - Mental nerve - Hard tissue landmarks.

\begin{abstract}
Objective. The goal of this ultrasound based cross-sectional study was to make use of ultrasound to determine the position of the mental foramen in relation to hard tissue landmarks. Material and methods. One hundred Black and Caucasian subjects were included. An ultrasound transducer was used to locate the mental foramina. Distances to various landmarks were measured and compared. Results. All mental foramina were visualised ultrasonographically. The mean distances to various landmarks from the mental foramen for the entire group on the right and left sides respectively were as follows: a) $22.8 \mathrm{~mm}$ (SD $2.04 \mathrm{~mm}$ ) and $22.8 \mathrm{~mm}$ (SD $2.0 \mathrm{~mm}$ ) to the cusp of the related tooth, b) $13.2 \mathrm{~mm}(\mathrm{SD} 1.6 \mathrm{~mm}$ ) and $13.2 \mathrm{~mm}$ (SD $1.6 \mathrm{~mm}$ ) to the inferior border of the mandible. The mean position of the mental foramen was found to be $63.4 \%$ (SD 1.8\%) of the distance from the cusp of the related tooth to the inferior border of the mandible on the right and $63.3 \%$ (SD 1.7\%) on the left. There were statistically significant differences between race groups and genders, but not between age groups. Conclusion. These results suggest that ultrasound is a sensitive modality to locate the mental foramen. There are minor, statistically significant (but clinically insignificant) differences in the position of the mental foramen with regard to various hard tissue landmarks.
\end{abstract}

\section{Introduction}

The mental foramen is located on either side of the mandible just below the corners of the lips, around the region of the root of the second premolar tooth (1). The mental nerve emerges from the mental foramen and provides sensation to the lower central portion of the face $(1,2)$.

Dentists, oral maxillofacial surgeons, emergency physicians, and plastic and reconstructive surgeons are required to be knowledgeable regarding the anatomy of the mental foramen and variations in its position, for the purpose of achieving local anaesthesia as well as planning various surgical procedures $(3,4)$. Procedures important to the anatomy of the mental foramen include: tooth extractions, root canal treatment, scaling, polishing, treatment of gingival disease, removal of cysts and tumors, repair of lower lip and chin lacerations, reconstructive soft tissue procedures, endodontic/orthogenetic surgery, fixation of bone fractures and implant placement (5-7). Variation in the anatomy and position of the mental foramen, with regard to race, age and gender, play an important role (8-12). The mental foramen and the various modalities useful in locating the mental foramen have been reviewed in detail elsewhere (13). 
Local anaesthesia infiltration and surgical procedures in the vicinity of the mental nerve may be complicated by temporary or permanent sensory dysfunction and paraesthesia as a result of injury to the mental nerve $(14,15)$. Therefore the accurate determination of the position of the mental foramen is important to all clinicians concerned.

The aim of this ultrasound based cross sectional study was to determine the position of the mental foramen in relation to hard tissue landmarks using ultrasound.

\section{Materials and methods}

In the preparation prior to this study, ultrasound echogenic markers were placed at the mandibular border and cusp tip to ensure that the image limits seen on the monitor screen correlated with the distances measured without markers (Figure 1 and 2).

In this study we enrolled 100 Adult Black and Caucasian (White and Asian) patients, older than 18 years who presented to the CMJAH ED (Figure 3). Patients

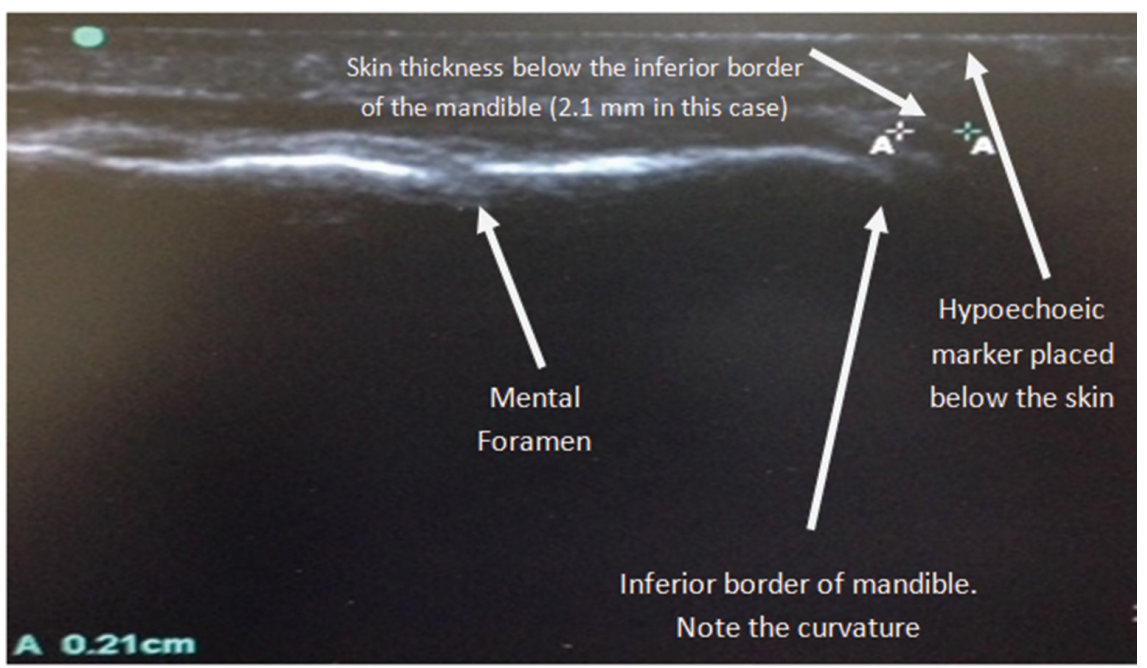

Figure 1 Ultrasound image showing the inferior border of the mandible and the mental foramen.

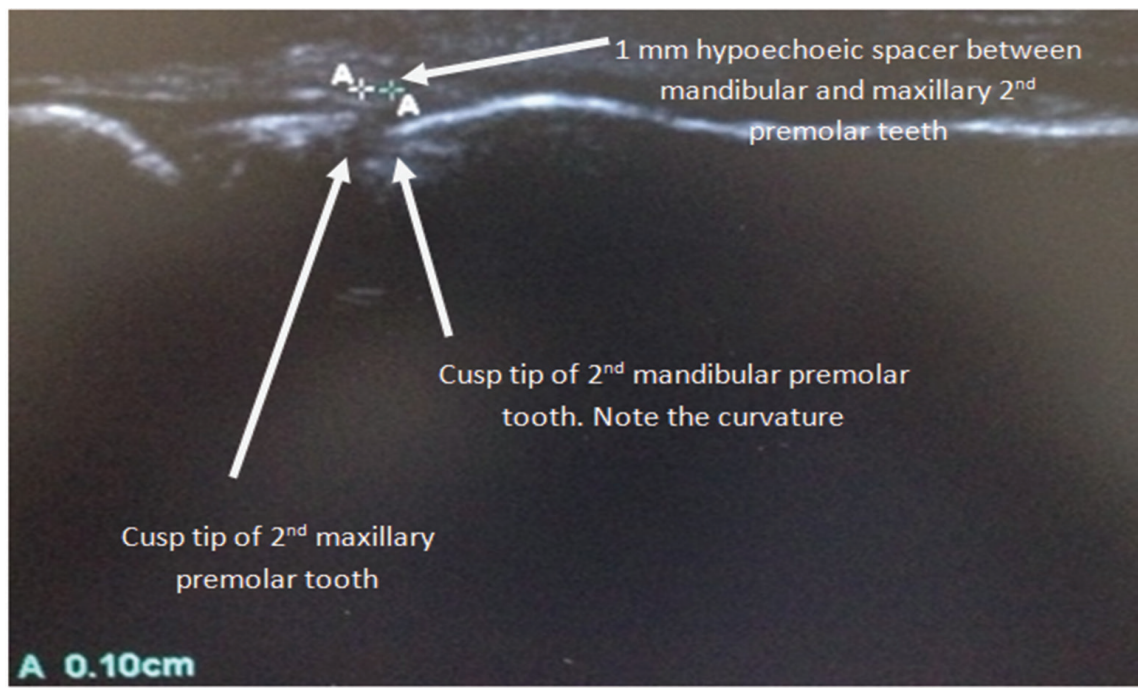

Figure 2 Ultrasound image showing cusp tips of the $2^{\text {nd }}$ premolar teeth with interposing $1 \mathrm{~mm}$ hypoechoeic spacer. 


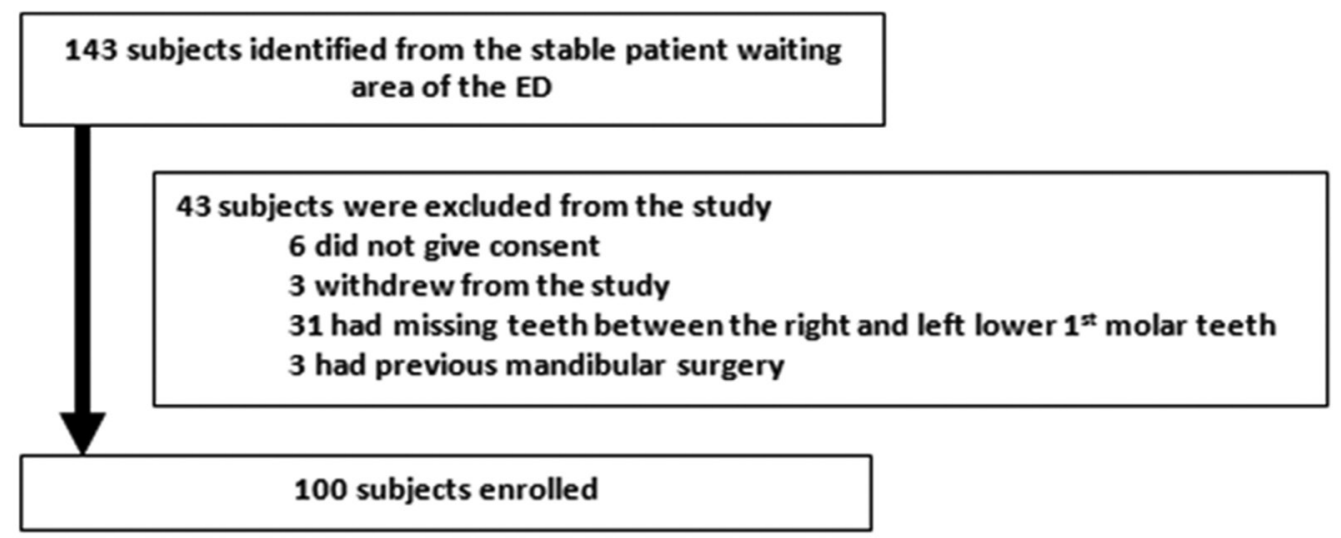

Figure 3 Exclusions and final sample for analysis.

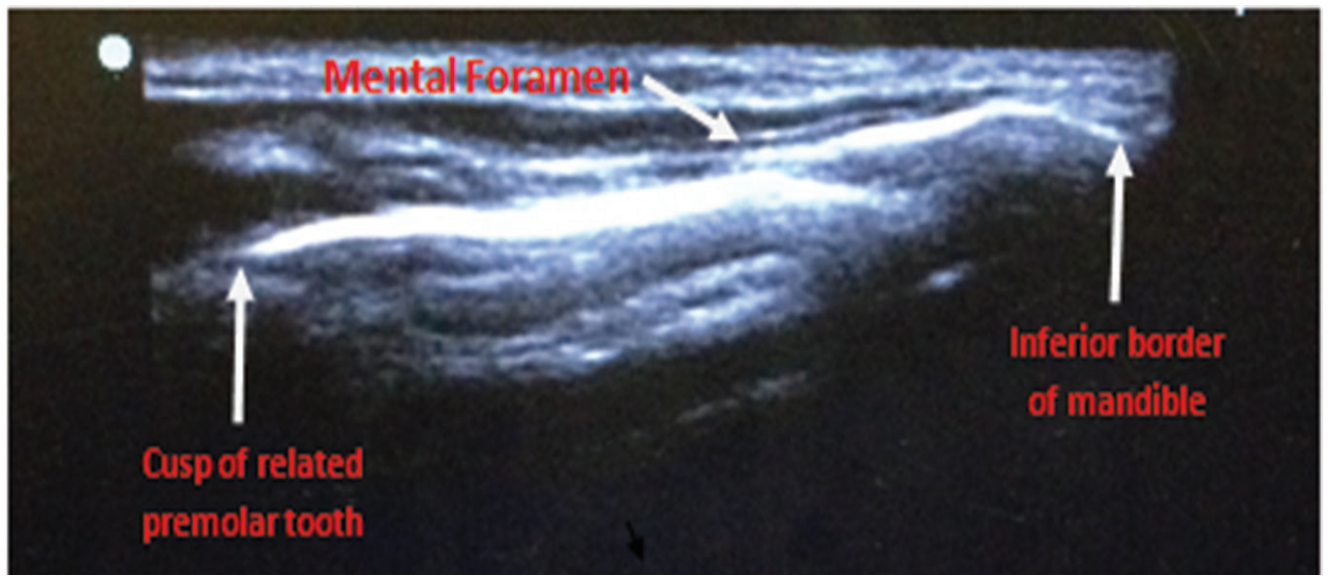

Figure 4 Ultrasound image of the mental foramen and its hard tissue relations. The mental foramen is easily identified as a break in the continuity of the bone in the vicinity just below the corner of the mouth.

were randomly selected from the ED queue at a time convenient to the researcher. The last patient waiting in the ED queue to see a doctor for his/her presenting complaint was approached first for participation in the study. Patients were approached in this manner so as not to lengthen their waiting time in the ED queue for the purpose of their visit. Potential participants were given an information leaflet. Eligible volunteers, who consented to participate in the study, were made to lie in the supine position in an examination cubicle. We used a Toshiba diagnostic ultrasound system (model SSA$510 \mathrm{~A})$ and a high frequency $(8 \mathrm{MHz})$ transducer (PLF.805ST) with the machine set on the "small parts" preset mode. The length of the transducer covered the distance between the related cusp tip and the inferior border of the mandible in all cases. Sonar gel (Konix ultrasound gel, Sanichem, Durban, South Africa) was applied to the ultrasound transducer once the machine was in running mode. The transducer, with the marker facing cranially, was gently applied just lateral to the mentum. The mental foramen was identified and the appropriate image frozen (Figure 4). The cusp to mental foramen and the inferior border of the mandible to mental foramen distances were measured and documented. Participants were asked to maintain a neutral facial ex- 
pression during measurements. The above procedure was repeated on the opposite side of the face. After documenting relevant data, excess gel was gently cleaned off and the volunteer thanked. Any difficulties experienced during the investigation were documented. Individuals with congenital / acquired facial distortion, a history of mandibular surgery and patients who had mandibular teeth missing between the right and left lower 1st molars were excluded from the study. Details of patient recruitment and exclusion are listed in the flow diagram in figure 3.

Patient confidentiality was respected at all times. Data collection sheets did not include personal data. Only relevant demographic data was included. The information gathered was protected by a coded numbering system, which was stored in a passwordprotected computer that was only accessible to the researcher.

\section{Ethics statement}

Permission to conduct the study was obtained from the head of department (H.O.D) of the CMJAH ED and the hospital management. Clearance was obtained from the $\mathrm{Hu}-$ man Research Ethics Committee of the University of the Witwatersrand (certificate no. M110920).

\section{Statistical analysis}

All data were captured from the data collection sheets by the primary investigator and entered into an electronic spreadsheet (Microsoft $^{\circledast}$ Excel $\left.^{\circledR}\right)$. STATA ${ }^{\circledR}$ version12.1 software (StataCorp LP) was used to analyze all data. Each volunteer was placed into an age category: a) 18-30 yrs, b) 31-40 yrs, c) 4150 yrs, d) 51-60 yrs, e) 61-70 yrs. Means and standard deviations were calculated for continuous variables (measurements obtained).
The means of measurements obtained (continuous variable) for age group, gender and race (categorical variables) were compared. Normal (Gaussian) distribution and equal variance of the data were confirmed using the Kolmogorov-Smirnov and Barnett's tests, respectively. Data were statistically analyzed using one-way ANOVA. Where appropriate, the Student's-T-test and Bonferroni post hoc analysis were performed. The level of significance was set at $\alpha=0.05$, $\mathrm{CI}=95 \%$. Study reporting conformed to STROBE guidelines (16).

\section{Results}

The total sample of 100 subjects consisted of 50 Blacks (27 males and 23 females) and 50 Caucasians (23 males and 27 females). The Caucasians were further subdivided into 25 Asians (13 males and 12 females) and 25 Whites (10 males and 15 females). The overall sex distribution was equal and (50 males and 50 females). The overall mean age of the study population was 35.7 years (SD 1.9 years).

All mental foramina (100\%) were ultrasonographically identified. Figures 5 and 6 respectively describe the hard tissue distances that were measured and the mean measurements for the entire group. Table 1 describes the age group frequencies of the various race groups studied and Table 2 describes the impact of race, gender and age on the position of the mental foramen, with regard to distances to hard tissue landmarks.

A significant difference was found between races and between genders for the distances from the mental foramen to the various hard tissue landmarks. However there were no statistically significant differences between age categories. This is presented in Table 2. 


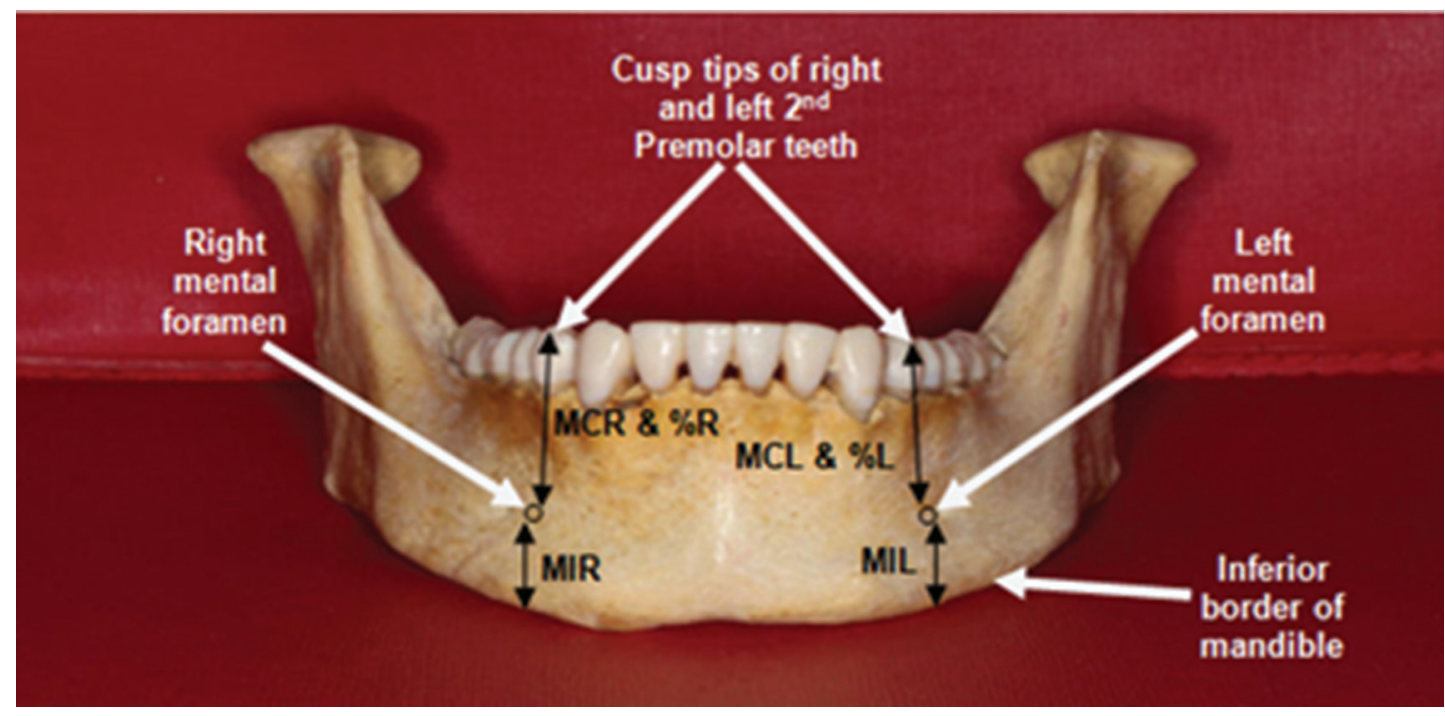

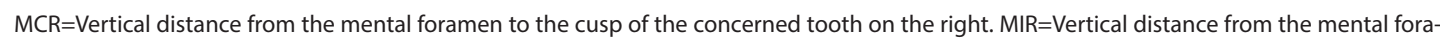
men to the inferior border of the mandible on the right. \% $R=$ The proportion of the distance (in percentage) of the position of the mental foramen from the cusp of the related tooth to the inferior border of the mandible on the right (i.e. MCR / MCR + MIR). MCL=Vertical distance from the mental foramen to the cusp of the concerned tooth on the left. MIL=Vertical distance from the mental foramen to the inferior border of the mandible on the left. \% $\mathrm{L}=$ The proportion of the distance (in percentage) of the position of the mental foramen from the cusp of the related tooth to the inferior border of the mandible on the left (i.e. MCL / MCL + MIL).

Figure 5 Frontal view of the mandible showing horizontal hard tissue measurements.

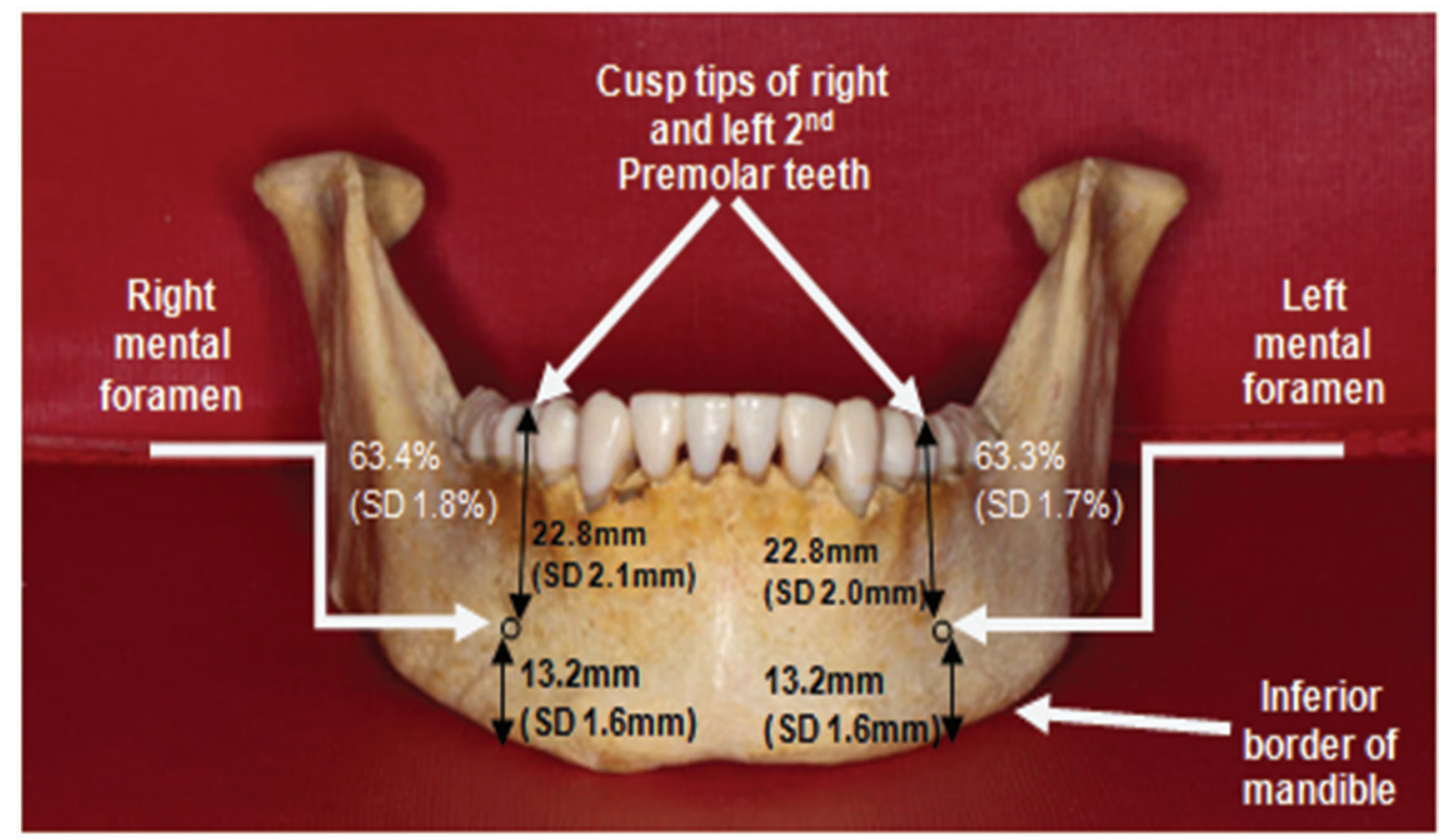

Figure 6 Frontal view of the mandible showing the various mean horizontal hard tissue measurements for the entire group of participants. 
Acta Medica Academica 2016;45:51-60

Table 1 Age group frequencies of the various race groups studied

\begin{tabular}{lllllll}
\hline \multirow{2}{*}{ Race } & \multicolumn{7}{l}{ Age Group (yrs) } \\
\cline { 2 - 7 } & $18-30$ & $31-40$ & $41-50$ & $51-60$ & $61-70$ & Mean (SD) \\
\hline Black & 18 & 20 & 8 & 3 & 1 & $34.7(10.4)$ \\
Asian & 13 & 6 & 3 & 3 & - & $33.5(11.6)$ \\
White & 9 & 3 & 5 & 7 & 1 & $39.9(11.6)$ \\
Total & 40 & 29 & 16 & 13 & 2 & $35.7(11.1)$ \\
\hline
\end{tabular}

Table 2 The impact of race, gender and age with regard to the distance from the mental foramen to various hard tissue landmarks

\begin{tabular}{|c|c|c|c|c|c|c|c|c|c|c|c|c|}
\hline \multirow{2}{*}{\multicolumn{2}{|c|}{ Distances }} & \multirow{2}{*}{$\begin{array}{l}\text { All } \\
\text { patients }\end{array}$} & \multicolumn{3}{|l|}{ Race } & \multicolumn{2}{|l|}{ Gender } & \multicolumn{5}{|c|}{ Age group (years) } \\
\hline & & & Black & Asian & White & Female & Male & $18-30$ & $31-40$ & $41-50$ & $51-60$ & $61-70$ \\
\hline \multirow{3}{*}{$\begin{array}{l}\text { MCR } \\
(\mathrm{mm})\end{array}$} & Mean & 22.8 & 23.5 & 22.1 & 21.9 & 21.5 & 24.0 & 22.3 & 23.4 & 23.3 & 22.2 & 20.9 \\
\hline & SD & 2 & 2.0 & 1.8 & 1.7 & 1.5 & 1.7 & 1.7 & 1.9 & 2.4 & 2.4 & 0.6 \\
\hline & & & \multicolumn{3}{|c|}{ ANOVA $(p=0.0009)$} & \multicolumn{2}{|c|}{$T$ test $(p=0.0000)$} & \multicolumn{5}{|c|}{ ANOVA $(p=0.0671)$} \\
\hline \multirow{3}{*}{$\begin{array}{l}\mathrm{MCL} \\
(\mathrm{mm})\end{array}$} & Mean & 22.8 & 23.5 & 22.1 & 22.1 & 21.6 & 24.0 & 22.4 & 22.4 & 23.4 & 22.3 & 20.8 \\
\hline & SD & 2 & 1.9 & 1.7 & 2.0 & 1.4 & 1.7 & 1.7 & 1.9 & 2.3 & 2.4 & 0.6 \\
\hline & & & \multicolumn{3}{|c|}{ ANOVA $(p=0.0023)$} & \multicolumn{2}{|c|}{$T$ test $(p=0.0000)$} & \multicolumn{5}{|c|}{ ANOVA $(p=0.0842)$} \\
\hline \multirow{3}{*}{$\begin{array}{l}\text { MIR } \\
(\mathrm{mm})\end{array}$} & Mean & 13.2 & 13.9 & 12.2 & 12.8 & 12.1 & 14.2 & 12.6 & 13.7 & 13.4 & 12.9 & 12.4 \\
\hline & SD & 1.6 & 1.4 & 1.5 & 1.6 & 1.2 & 1.3 & 1.6 & 1.6 & 1.7 & 1.9 & 0.4 \\
\hline & & & \multicolumn{3}{|c|}{ ANOVA $(p=0.0000)$} & \multicolumn{2}{|c|}{$T$ test $(p=0.0000)$} & \multicolumn{5}{|c|}{ ANOVA $(p=0.2487)$} \\
\hline \multirow{3}{*}{$\begin{array}{l}\text { MIL } \\
(\mathrm{mm})\end{array}$} & Mean & 13.2 & 13.9 & 12.2 & 12.7 & 12.1 & 14.2 & 12.8 & 13.7 & 13.3 & 12.9 & 12.5 \\
\hline & SD & 1.6 & 1.4 & 1.4 & 1.6 & 1.2 & 1.3 & 1.5 & 1.5 & 1.8 & 1.8 & 0.8 \\
\hline & & & \multicolumn{3}{|c|}{ ANOVA $(p=0.0000)$} & \multicolumn{2}{|c|}{$T$ test $(p=0.0001)$} & \multicolumn{5}{|c|}{ ANOVA $(p=0.2263)$} \\
\hline \multirow{3}{*}{$\begin{array}{l}\% R \\
(\mathrm{~mm})\end{array}$} & Mean & 63.4 & 62.9 & 64.5 & 63.4 & 63.9 & 62.9 & 63.6 & 63.2 & 63.6 & 63.2 & 62.8 \\
\hline & SD & 1.8 & 1.3 & 2.0 & 2.0 & 1.9 & 1.5 & 2.0 & 1.4 & 1.8 & 1.9 & 0.0 \\
\hline & & & \multicolumn{3}{|c|}{ ANOVA $(p=0.0007)$} & \multicolumn{2}{|c|}{$T$ test $(p=0.0037)$} & \multicolumn{5}{|c|}{ ANOVA $(p=0.8039)$} \\
\hline \multirow{3}{*}{$\begin{array}{l}\% \mathrm{~L} \\
(\mathrm{~mm})\end{array}$} & Mean & 63.3 & 62.8 & 64.3 & 63.4 & 63.9 & 62.8 & 63.6 & 63.1 & 63.5 & 63.1 & 62.4 \\
\hline & SD & 1.7 & 1.5 & 1.8 & 1.9 & 1.8 & 1.6 & 1.9 & 1.6 & 1.8 & 1.6 & 1.0 \\
\hline & & & \multicolumn{3}{|c|}{ ANOVA $(p=0.0020)$} & \multicolumn{2}{|c|}{$T$ test $(p=0.0019)$} & \multicolumn{5}{|c|}{ ANOVA $(p=0.6668)$} \\
\hline
\end{tabular}

$M C R=$ Vertical distance from the mental foramen to the cusp of the concerned tooth on the right; MIR=Vertical distance from the mental foramen to the inferior border of the mandible on the right; \% $\mathrm{R}=$ The proportion of the distance (in percentage) of the position of the mental foramen from the cusp of the related tooth to the inferior border of the mandible on the right (i.e. MCR MCR + MIR); MCL=Vertical distance from the mental foramen to the cusp of the concerned tooth on the left; MIL=Vertical distance from the mental foramen to the inferior border of the mandible on the left. \% $\mathrm{L}=$ The proportion of the distance (in percentage) of the position of the mental foramen from the cusp of the related tooth to the inferior border of the mandible on the left (i.e. MCL/MCL+MIL).

\section{Discussion}

This was a prospective, cross-sectional observational study of patients who presented to a single center ED (Charlotte Maxeke Johanesburg Academic Hospital (CMJAH), Johannesburg, South Africa) between February 2012 and March 2013. CMJAH is a tertiary care facility in a large urban envi- ronment, and is affiliated with the University of the Witwatersrand.

In this study, we identified $100 \%$ of mental foraminae by ultrasound. By applying the ultrasound probe just lateral to the mentum, the mental foramen is easily recognized as a break in the continuity of the bone. There are no other similar ultrasonographic structures that may be confused with the mental 
foramen in this region. Jacobs et al. reported detection of the mental foramen in $94 \%$ of panoramic radiographs, and only $49 \%$ were clearly visible (17), whilst the mental foramen was visualized in only $84.2 \%$ of cases in an Iranian study that also assessed panoramic radiographs (18). An earlier study that assessed periapical films reported detection rates of the mental foramen in only $46.8 \%$ of cases (19). Therefore the use of ultrasonography to identify the mental foramen may be regarded as superior to panoramic and periapical films. It is also a safer option, with no known side effects or risk of radiation exposure (20).

Sixty-nine percent of subjects were under the age of 40 years and only $2 \%$ of subjects were older than 60 years. The reason that most of our subjects were under 40 years of age was due to the fact that with advancement in age, the incidence of missing teeth between the right and left mandibular 1st molars is higher. Therefore, many potential subjects that were approached to participate in the study were excluded as they had missing teeth between the right and left 1st mandibular molars.

The mean vertical distance of the entire group of subjects from the buccal cusp tip of the concerned tooth to the mental foramen was $22.8 \mathrm{~mm}$ (SD $2.0 \mathrm{~mm}$ ) on the right and $22.8 \mathrm{~mm}$ (SD $2.0 \mathrm{~mm}$ ) on the left side. Differences between all race groups were minimal at around $1 \mathrm{~mm}$. Although these differences are statistically significant, they are however minimal and are not regarded significant from a practical or clinical point of view. In males, the mean distances were about 2.5 $\mathrm{mm}$ longer than in females $(\mathrm{p}<0.05)$. Average distances of $23.34 \mathrm{~mm}$ and $25.69 \mathrm{~mm}$ have been recorded in Chinese and Korean populations respectively $(21,22)$.

The mean vertical distance of the entire group of subjects from the inferior border of the mandible to the mental foramen was 13.2 $\mathrm{mm}$ (SD $1.6 \mathrm{~mm}$ ) on the right and $13.2 \mathrm{~mm}$ (SD $1.6 \mathrm{~mm}$ ) on the left side. The mean dif- ference between racial groups was approximately $1 \mathrm{~mm}(\mathrm{p}<0.05)$. In males the mean distances were about $2 \mathrm{~mm}$ longer than in females. In studies on American and Indian subjects, the mean distance has been reported as $12.9 \mathrm{~mm}$ and $16.5 \mathrm{~mm}$ respectively $(9,23)$. Other studies documented distances between the above $(10,21,22,24-28)$.

No previous published studies have compared differences between race groups, between genders or between age groups with regard to the buccal tip to mental foramen distance or the inferior border of the mandible to mental foramen distance. However the distance from the mental foramen to the symphysis menti, and from the mental foramen to the posterior border of the ramus has been previously studied and compared between population groups $(10,29,30)$.

The mean position of the mental foramen for the entire group of subjects in this study was $63.4 \%$ (SD 1.8\%) of the distance from the cusp of the related tooth to the inferior border of the mandible on the right $(\% \mathrm{R})$ and $63.3 \%(\mathrm{SD} 1.7 \%)$ on the left $(\% \mathrm{~L})$ side. The mean position of the mental foramen was lowest in Asians, then Whites and then Blacks. They were all however within $2 \%$ of each other. The mental foramen was located about $1 \mathrm{~mm}$ lower in females compared to males $(\mathrm{p}<0.05)$. An American study located the mental foramen at an average of approximately $60 \%$ of the distance between the buccal cusp tip and the inferior border of the mandible (31). A Korean study compared dry skulls with panoramic radiographs, and concluded that the average distance ratio from the buccal cusp tip to the inferior border of the mandible was $60.6 \%$ on dry skulls and $63.6 \%$ on panoramic radiographs (22). A study using panoramic $\mathrm{X}$-ray images looked at ideally positioned and systematically mis-positioned skulls, to evaluate for errors in linear measurements and symmetry ratios. The study concluded that panoramic radiographs should be in- 
terpreted with caution for absolute measurements or relative comparisons, even when internal fiducial calibration for image distortion of anatomy is used (32). Ultrasonographic techniques make use of direct measurement and do not have the negative effect of radiographs, where angles and curves are not taken into account.

A limitation to the use of ultrasound includes the fact that ultrasonography is operator dependent. Therefore, all ultrasound examinations and data collection were conducted by the primary investigator, who is certified for emergency ultrasound by the College of Emergency Medicine of South Africa. The study was fully supervised by a faculty member of the division of emergency ultrasound of the College of Emergency Medicine of South Africa. Another limitation to our study is that we excluded patients with congenital / acquired facial distortions, patients with a history of mandibular surgery, and patients who had mandibular teeth missing between the right and left lower 1st molars. Perhaps the mental foramen may not have been as easily found with ultrasonography in these patients as a result of positional change or distortion of the mental foramen. Studies have reported a change in the position of the mental foramen with regard to hard tissue landmarks in subjects with advanced age, tooth wear and loss of teeth $(8,11,12,33)$. We did not find any statistically significant differences between age groups in our study. A likely reason is that more than two thirds of the subjects in our study were under 40 years old, and only $2 \%$ of the subjects were older than 60 years. Further studies using ultrasonography and hard tissue landmarks will be required to see if the same holds true in patients with advanced age, tooth wear and tooth loss.

\section{Conclusion}

Ultrasonography, regarded as the 21st century stethoscope in the Emergency Depart- ment (34), is a cost effective, time saving, non-invasive, safe modality, with no risk of radiation exposure (20). It has many uses in the Emergency Department, including regional nerve block anesthesia, and can be used as a diagnostic, as well as an interventional tool (35). Theoretically, the use of ultrasonography for mental nerve blocks would decrease the need for local anesthesia, increase first time success rates and decrease complication rates. Traxler et al. used ultrasound in 1992 to determine the alveolar ridge width for purposes of dental implants. They also commented that ultrasound provided accurate information about the position of the mental foramen, as a secondary finding (36). Recently, Møystad and colleagues used ultrasound to evaluate the size of the mental foramen in patients with unilateral neurosensory dysfunction after third molar removal (37). More recently, Chan and colleagues, in a proof of concept study, compared CBCT scans with real-time ultrasound. They commented that hard tissue surfaces, including enamel, root dentin, and bone, as well as soft tissues and the mental foramen, were easily visualized. Various ultrasonographic measurements correlated well with the measurements obtained from CBCT scans (38). Point of care / hand held ultrasound devices, as well as recent advances in $3 \mathrm{D}$ ultrasonography, have the potential to revolutionize the practice of dento-maxillofacial surgery. A limitation to the use of ultrasonography is that it is operator dependent (34).

\section{What is already known on this topic}

The mental foramen is an important landmark for dentists, oral maxillofacial surgeons, emergency physicians, and plastic and reconstructive surgeons. The position of the mental foramen and nerve has been well reported in the dento-maxillofacial setting on cadaver specimens, intra-operatively and radiologically. The literature regarding the role of ultrasound in finding the mental foramen and other oro-facial structures is rather sparse.

What this study adds

Ultrasound has $100 \%$ sensitivity in accurately locating the mental foramen in normal human mandibles. There were mi- 
nor, statistically significant (but clinically insignificant) differences in the position of the mental foramen across race, gender and age, with regard to various hard tissue landmarks. Point of care / hand held ultrasound devices have the potential to revolutionize the practice of dento-maxillofacial surgery.

Acknowledgements: We are grateful to the Charlotte Maxeke Johannesburg Academic Hospital for allowing us to use the ultrasound machine.

Authors' contributions: Conception and design: AL and ZM; Acquisition, analysis and interpretation of data: AL and ZM; Drafting the article: AL and ZM; Revising it critically for important intellectual content: $\mathrm{AL}$ and $\mathrm{ZM}$; Approved final version of the manuscript: $\mathrm{AL}$ and $\mathrm{ZM}$.

Conflict of interest: The authors declare that they have no conflict of interest.

\section{References}

1. Haghanifar S, Rokouei M. Radiographic evaluation of the mental foramen in a selected Iranian population. Indian J Dent Res. 2009;20(2):150-2.

2. Hell B, Freitag V. Lower lip carcinoma. Infiltration of the mandible along the mental nerve. J Craniomaxillofac Surg. 1988;16(2):76-9.

3. Song WC, Kim SH, Paik DJ, Han SH, Hu KS, Kim $\mathrm{HJ}$, et al. Location of the infraorbital and mental foramen with reference to the soft-tissue landmarks. Plast Reconstr Surg. 2007;120(5):1343-7.

4. von Arx T, Friedli M, Sendi P, Lozanoff S, Bornstein MM. Location and dimensions of the mental foramen: a radiographic analysis by using cone-beam computed tomography. J Endod. 2013;39(12):1522-8.

5. Gianni AB, D’Orto O, Biglioli F, Bozzetti A, Brusati R. Neurosensory alterations of the inferior alveolar and mental nerve after genioplasty alone or associated with sagittal osteotomy of the mandibular ramus. J Craniomaxillofac Surg. 2002;30(5):295-303.

6. Juodzbalys G, Wang H-L, Sabalys G. Anatomy of Mandibular Vital Structures. Part II: Mandibular Incisive Canal, Mental Foramen and Associated Neurovascular Bundles in Relation with Dental Implantology. J Oral Maxillofac Res. 2010;1(1):e3.

7. Song Q, Li S, Patil PM. Inferior alveolar and mental nerve injuries associated with open reduction and internal fixation of mandibular fractures: A Seven Year retrospective study. J Craniomaxillofac Surg. 2014;42(7):1378-81.
8. Al-Khateeb T, Al-Hadi Hamasha A, Ababneh KT. Position of the mental foramen in a northern regional Jordanian population. Surg Radiol Anat. 2007;29(3):231-7.

9. Sankar DK, Bhanu SP, Susan PJ. Morphometrical and morphological study of mental foramen in dry dentulous mandibles of South Andhra population of India. Indian J Dent Res. 2011;22(4):5426.

10. Santini A, Alayan I. A comparative anthropometric study of the position of the mental foramen in three populations. Br Dent J. 2012;212(4):E7.

11. Chrcanovic BR, Abreu MHNG, Custódio ALN. Morphological variation in dentate and edentulous human mandibles. Surg Radiol Anat. 2011;33(3):203-13.

12. Soikkonen K, Wolf J, Ainamo A, Xie Q. Changes in the position of the mental foramen as a result of alveolar atrophy. J Oral Rehabil. 1995;22(11):8313.

13. Laher AE, Wells M, Motara F, Kramer E, Moolla M, Mahomed Z. Finding the mental foramen. Surg Radiol Anat. Epub 2015 Oct 13.

14. Loudon J. Beware the mental foramen. Br Dent J. 2011;210(7):293.

15. Smith $M H$, Lung KE. Nerve injuries after dental injection: a review of the literature. J Can Dent Assoc. 2006;72(6):559-64.

16. von Elm E, Altman DG, Egger M, Pocock SJ, Gøtzsche PC, Vandenbroucke JP. The Strengthening the Reporting of Observational Studies in Epidemiology (STROBE) statement: guidelines for reporting observational studies. Lancet. 2007;370(9596):1453-7.

17. Jacobs R, Mraiwa N, Van Steenberghe D, Sanderink G, Quirynen M. Appearance of the mandibular incisive canal on panoramic radiographs. Surg Radiol Anat. 2004;26(4):329-33.

18. Jalili MR, Esmaeelinejad M, Bayat M, Aghdasi MM. Appearance of anatomical structures of mandible on panoramic radiographs in Iranian population. Acta Odontol Scand. 2012;70(5):3849.

19. Fishel D, Buchner A, Hershkowith A, Kaffe I. Roentgenologic study of the mental foramen. Oral Surg Oral Med Oral Pathol. 1976;41(5):682-6.

20. Claudon M, Guillaume L. Diagnostic imaging and radiation hazards [in French]. Rev Prat. 2015;65(1):79-81.

21. Guo JL, Su L, Zhao JL, Yang L, Lv DL, Li YQ, et al. Location of mental foramen based on soft- and hard-tissue landmarks in a chinese population. J Craniofac Surg. 2009;20(6):2235-7. 
22. Kim IS, Kim SG, Kim YK, Kim JD. Position of the mental foramen in a Korean population: a clinical and radiographic study. Implant Dent. 2006;15(4):404-11.

23. Smith JD, Surek CC, Cortez EA. Localization of the supraorbital, infraorbital, and mental foramina using palpable, bony landmarks. Clin Anat. Epub 2010 Feb 18.

24. Smajilagić A, Dilberović F. Clinical and anatomy study of the human mental foramen. Bosn J Basic Med Sci. 2004;4(3):15-23.

25. Gupta T. Localization of important facial foramina encountered in maxillo-facial surgery. Clin Anat. 2008;21(7):633-40.

26. Igbigbi PS, Lebona S. The position and dimensions of the mental foramen in adult Malawian mandibles. West Afr J Med. 2005;24(3):184-9.

27. Mbajiorgu EF, Mawera G, Asala SA, Zivanovic S. Position of the mental foramen in adult black Zimbabwean mandibles: a clinical anatomical study. Cent Afr J Med. 1998;44(2):24-30.

28. Oguz O, Bozkir MG. Evaluation of location of mandibular and mental foramina in dry, young, adult human male, dentulous mandibles. West Indian Med J. 2002;51(1):14-6.

29. Santini A, Land M. A comparison of the position of the mental foramen in Chinese and British mandibles. Acta Anat (Basel). 1990;137(3):20812.

30. Koppe T. Summary of: A comparative anthropometric study of the position of the mental foramen in three populations. Br Dent J. 2012;212(4):1889.
31. Phillips JL, Weller RN, Kulild JC. The mental foramen: 1 . Size, orientation, and positional relationship to the mandibular second premolar. J Endod. 1990;16(5):221-3.

32. Laster WS, Ludlow JB, Bailey LJ, Hershey HG. Accuracy of measurements of mandibular anatomy and prediction of asymmetry in panoramic radiographic images. Dentomaxillofac Radiol. 2005;34(6):343-9.

33. Green RM, Darvell BW. Tooth wear and the position of the mental foramen. Am J Phys Anthropol. 1988;77(1):69-75.

34. Coşkun F, Akıncı E, Ceyhan MA, Sahin Kavaklı H. Our new stethoscope in the emergency department: handheld ultrasound. Ulus Travma Acil Cerrahi Derg. 2011;17(6):488-92.

35. Wells M. Local and Regional Anaesthesia in the Emergency Department Made Easy - Elsevier. 1st ed. London: Churchill Livingstone Elsevier; 2010.

36. Traxler M, Ulm C, Solar P, Lill W. Sonographic measurement versus mapping for determination of residual ridge width. J Prosthet Dent. 1992;67(3):358-61.

37. Møystad A, Bjørnland T, Friedland B, Donoff RB. Ultrasonographic pilot study of mental foramen size, with and without postoperative neurosensory dysfunction. Oral Surg Oral Med Oral Pathol Oral Radiol. 2015;120(2):275-80.

38. Chan HL, Wang HL, Fowlkes JB, Giannobile WV, Kripfgans OD. Non-ionizing real-time ultrasonography in implant and oral surgery: A feasibility study. Clin Oral Implants Res. Epub 2016 Mar 19. 